\title{
mtDNA analysis in Portuguese populations (Central Portugal and Azores Islands): polymorphic sites in control region sequences
}

\author{
M. Carvalho ${ }^{\text {a }}$, C. Mendes ${ }^{\text {a }}$, H. Antunes ${ }^{\text {a }}$, M.J. Anjos ${ }^{\text {a }}$, L. Andrade ${ }^{\text {a }}$, \\ V. Lopes ${ }^{\mathrm{a}}$, D.N. Vieira ${ }^{\mathrm{a}, \mathrm{b}}$, M.C. Vide ${ }^{\mathrm{a}, *}$ \\ anstituto Nacional de Medicina Legal, Delegação de Coimbra, Serviço de Genética Forense, \\ Largo da Sé Nova, 3000-213 Coimbra, Portugal \\ ${ }^{\mathrm{b}}$ Faculty of Medicine, University of Coimbra, Coimbra, Portugal
}

\begin{abstract}
Background: The polymorphism of the two hypervariable segments (HVI and HVII) of the control region of mtDNA was analyzed in a population of 81 unrelated individuals from Central Portugal and 48 from the Azores Islands, using a fluorescent-based electrophoresis sequencing method. Methods: Sequences have been obtained with ABI PRISM0 Big Dye Terminator and dRhodamine Terminator Cycle Sequencing Ready Reaction Kits, with Amplitaq DNA Polymerase FS, and have been detected with ABI PRISM 377 DNA sequencer. Results: In the Central Portugal population $(n=81)$, we observed 69 polymorphic sites of sequence in HVI region and 44 in HVII region. In the Azores population $(n=48)$, we observed 48 polymorphic sites of sequence in HVI region and 24 in HVII region. Conclusions: Nucleotide substitution rather than insertion/deletion ( 1 or $2 \mathrm{bp}$ ) was the majority of variation. The distribution showed a large bias towards transitional changes than transversional changes. Our sequencing results are similar to other Caucasian population data.

(C) 2003 Elsevier Science B.V. All rights reserved.
\end{abstract}

Keywords: mtDNA; Central Portugal; Azores Islands; Population genetics

\section{Introduction}

The control region of mtDNA has become a useful tool in forensic genetics because we can analyse hair shafts, bones and samples with very little or degraded DNA. The mtDNA

\footnotetext{
${ }^{*}$ Corresponding author. Tel.: +351-239-854-230; fax: +351-239-820-549.

E-mail address: movide@ci.uc.pt (M.C. Vide).
} 
is highly polymorphic and exists in multicopies per cell. The small molecules present a double stranded circular structure of $16569 \mathrm{bp}$ [1].

The aim of this study was to determine the polymorphism of the HVRI and HVRII in two Portuguese populations: Central Portugal and Azores Islands. The results were compared with other Caucasian populations.

\section{Material and methods}

DNA was extracted from bloodstains (81 unrelated individuals from Central Portugal and 48 from the Azores Islands), using the Chelex 100 extraction method [2].

Primers and amplification conditions were as described by Wilson et al. [3].

PCR products were purified with MicroSpin Sephadex G-50. Purified DNA was estimated using the Phastsystem to determine the optimal PCR product quantity for the sequencing analysis.

Sequencing reactions were performed in both directions (forward and reverse) using the ABI Prism dRhodamine or Big Dye Terminator Cycle Sequencing Ready Reaction Kits (Applied Biosystems) and the same primers as the amplification reactions. After sequencing, samples were purified by $\mathrm{MgCl}_{2} / \mathrm{ETOH}$ precipitation and analysed on $\mathrm{ABI}$ Prism 377 DNA Sequencer.

The nucleotide and sequence diversity was estimated as described by Nei and Tajima [4].

\section{Results}

In the Central Portugal population $(n=81)$, we observed 58 different sequences for HVRI and 49 for HVRII. HVRI showed 69 polymorphic sites and HVRII showed 44 polymorphic sites (Table 1).

In this population, we found homology with the CRS only in HVRI (14 individuals). The HVRI showed the four polymorphic sites with a high frequency at positions 16126 (T-C 17\%), 16189 (T-C 22\%), 16294 (C-T 11\%) and 16311 (T-C 12\%). In HVRII, all individuals revealed a transition $\mathrm{A}-\mathrm{G}$ at position 263 . At position $303-310$, the majority of sequences carried 8/9 C nucleotides instead of the 7 reported by Anderson. At position 311-315, the majority of sequences carried 6/7 C nucleotides instead of the 5 in the CRS.

In the Azores population ( $n=48)$, we observed 35 different sequences for HVRI and 31 for HVRII. HVRI showed 48 polymorphic sites and HVRII showed 24 polymorphic sites (Table 1).

In this population, we found homology with CRS only in HVRI (seven individuals). The HVRI showed the four polymorphic sites with a high frequency at positions 16126 (T-C 25\%), 16189 (T-C 12.5\%), 16294 (C-T 16.6\%) and 16311 (T-C 14.6\%). The HVRII revealed the same polymorphic sites as Central Portugal at positions 263 and $303-$ 310; however, at position 311-315, almost all sequences carried $6 \mathrm{C}$ nucleotides, instead of the 5 in the CRS.

The main variation detected in our populations is due to nucleotide substitutions, rather than insertion/deletion mutational events. The distribution showed a large bias towards 
Table 1

The comparison between all performed sequences and the Cambridge Reference Sequence (CRS)

\begin{tabular}{|c|c|c|c|c|c|c|c|c|}
\hline & Cen & 1 Portugal & & & $\mathrm{Az}$ & Islands & & \\
\hline HVI & 58 & ferent sequences & & & 35 & ferent sequences & & \\
\hline & 4 & Different sequences & 2 & Times & 4 & Different sequences & 2 & Times \\
\hline & 3 & were found & 3 & & & were found & & \\
\hline & 51 & Unique sequences & & & 31 & Unique sequences & & \\
\hline & 14 & $\begin{array}{l}\text { Sequences homologues } \\
\text { with CRS }\end{array}$ & & & 10 & $\begin{array}{l}\text { Sequences homolog } \\
\text { with CRS }\end{array}$ & & \\
\hline HVII & 49 & ferent sequences & & & 31 & ferent sequences & & \\
\hline & 8 & Different sequences & 2 & Times & 2 & Different sequences & 2 & Times \\
\hline & 2 & were found & 3 & & 2 & were found & 3 & \\
\hline & 1 & Different sequence & 4 & Times & 1 & Different sequence & 6 & Times \\
\hline & 1 & were found & 9 & & 1 & were found & 7 & \\
\hline & 1 & & 10 & & & & & \\
\hline & 36 & Unique sequences & & & 25 & Unique sequences & & \\
\hline
\end{tabular}

transitional changes rather than transversional changes. The number of pyrimidine transitions is greater than the purine transitions in HVRI, in both populations analysed. However, in HVRII, the opposite occurs: no transversion could be observed in HVRII from Azores Islands data (Table 2).

A polycytosine stretch occurred in both hypervariable segments. These regions are often heteroplasmic, having populations of mtDNA molecules differing in the number of Cs within the $\mathrm{C}$ stretch (poly-C).

Length polymorphism is often observed in HVRI, when a homopolymeric tract of Cs is generated by the occurrence of a $\mathrm{T}-\mathrm{C}$ transition at position 16189 (Bendall and Sykes

Table 2

Sequence polymorphism within the variable regions of mtDNA of 81/48 unrelated individuals of Central Portugal and Azores Islands

\begin{tabular}{llllll}
\hline & & $\begin{array}{l}\text { HVR I } \\
\text { Portugal }\end{array}$ & $\begin{array}{l}\text { HVR I } \\
\text { Azores }\end{array}$ & $\begin{array}{l}\text { HVRII } \\
\text { Portugal }\end{array}$ & $\begin{array}{l}\text { HVR II } \\
\text { Azores }\end{array}$ \\
\hline $\begin{array}{l}\text { Total number of sequence } \\
\text { polymorphism }\end{array}$ & & 193 & 115 & 358 & 216 \\
$\begin{array}{l}\text { Transition: Transversion ratio } \\
\text { Pyrimidine transitions }\end{array}$ & & $176: 17$ & $108: 7$ & $217: 5$ & $136: 0$ \\
& $\mathrm{~T} \rightarrow \mathrm{C}$ & 82 & 43 & 57 & 32 \\
Purine transitions & $\mathrm{C} \rightarrow \mathrm{T}$ & 61 & 46 & 23 & 19 \\
& $\mathrm{~A} \rightarrow \mathrm{G}$ & 24 & 6 & 124 & 81 \\
Transversions & $\mathrm{G} \rightarrow \mathrm{A}$ & 13 & 13 & 13 & 4 \\
& $\mathrm{C} \rightarrow \mathrm{A}$ & 3 & 2 & 1 & - \\
& $\mathrm{A} \rightarrow \mathrm{C}$ & 10 & 2 & - & - \\
& $\mathrm{G} \rightarrow \mathrm{C}$ & 2 & - & 3 & - \\
& $\mathrm{A} \rightarrow \mathrm{T}$ & 1 & 2 & - & - \\
Insertions & $\mathrm{C} \rightarrow \mathrm{G}$ & 1 & 1 & 1 & - \\
& $\mathrm{C}$ & $16189(1 \mathrm{pb})$ & $16189(1 \mathrm{pb})$ & $309(1-2 \mathrm{pb})$ & $309(1-2 \mathrm{pb})$ \\
& & & & $315(1-2 \mathrm{pb})$ & $315(1 \mathrm{pb})$ \\
\hline
\end{tabular}


Table 3

HVR I and HVR II mtDNA polymorphism: a comparison between Azores Islands and Central Portuguese sample

\begin{tabular}{|c|c|c|c|c|c|c|c|c|c|c|}
\hline & \multicolumn{5}{|c|}{ HVR I } & \multicolumn{5}{|c|}{ HVR II } \\
\hline & $N$ & $K$ & $A$ & $\pi$ & $J$ & $N$ & $K$ & $A$ & $\pi$ & $J$ \\
\hline Azores Islands & 48 & 35 & 48 & 0.0113 & 0.9557 & 48 & 31 & 24 & 0.0137 & 0.9610 \\
\hline Central Portugal & 81 & 58 & 69 & 0.0112 & 0.9392 & 81 & 49 & 44 & 0.0136 & 0.9702 \\
\hline
\end{tabular}

$N$-sample size; $K$-number of different sequences found; $A$-number of variable nucleotide positions; $\pi$ nucleotide diversity; $J$-sequence diversity.

[5]). This transition was observed in $20 \%$ of samples analysed from Central Portugal and $10 \%$ from Azores Islands.

The variation in each population is given by sequence diversity value, $J$ (Table 3 ). In our study, $J=0.9392$ for HVRI and $J=0.9702$ for HVRII (Central Portugal), and $J=0.9557$ for HVRI and $J=0.9610$ for HVRII (Azores Islands).

The nucleotide diversity values (Table 3 ) were $\pi=0.0112$ for HVRI and $\pi=0.0136$ for HVRII (Central Portugal), and $\pi=0.0113$ for HVRI and $\pi=0.0137$ for HVRII (Azores Islands).

\section{Discussion}

In both populations (Central Portugal and Azores Islands), the most frequent mutational events are transitions $\mathrm{T}-\mathrm{C}$ and $\mathrm{C}-\mathrm{T}$.

Table 4

Sequence diversity observed in HVR I in several populations

\begin{tabular}{lrllll}
\hline Population & $N$ & $K$ & $A$ & $\pi$ & $J$ \\
\hline Galician & 92 & 53 & 56 & 0.0087 & 0.9295 \\
Basque & 106 & 52 & 52 & 0.0081 & 0.9362 \\
Welsh & 92 & 48 & 51 & 0.0094 & 0.9307 \\
Portugal (Central) & $\mathbf{8 1}$ & $\mathbf{5 8}$ & $\mathbf{6 9}$ & $\mathbf{0 . 0 1 1 2}$ & $\mathbf{0 . 9 3 9 2}$ \\
Portugal (Azores) & $\mathbf{4 8}$ & $\mathbf{3 5}$ & $\mathbf{4 8}$ & $\mathbf{0 . 0 1 1 3}$ & $\mathbf{0 . 9 5 5 7}$ \\
Portugal (North) & 100 & 67 & 71 & 0.013 & - \\
Portugal (Central) & 82 & 62 & 66 & 0.014 & - \\
Portugal (South) & 59 & 41 & 54 & 0.013 & 0.9760 \\
British & 100 & 71 & 67 & 0.012 & 0.9834 \\
Spain & 89 & 70 & 69 & 0.014 & 0.9685 \\
Tuscan & 49 & 40 & 55 & 0.014 & 0.9879 \\
Turks & 96 & 79 & 82 & 0.015 & 0.9954 \\
Middle East & 42 & 38 & 59 & 0.020 &
\end{tabular}

$N$-sample size; $K$-number of different sequences found; $A$-number of variable nucleotides positions; $\pi$ nucleotide diversity; $J$-sequence diversity.

Population sources: Galician [6], Basque [7], Welsh [8], Portuguese (Central and Azores) (present study in bold), Portuguese (North, Central and South) [9], British [7], Spain [7], Tuscan [7], Turks [7], Middle-East [7]. All values in all populations are based on the analysis of a fragment of 360 nucleotides, from 16024 to 16383 [1]. 
The obtained values for sequence and nucleotide diversity reveal a substantial similarity with the described data for other Caucasian populations, namely other Portuguese populations (Table 4).

\section{References}

[1] S. Anderson, A.T. Bankier, B.G. Barrel, M.H. De Bruijn, A.R. Coulson, F. Sanger, P.H. Schreier, A.J.H. Smith, R. Staden, G. Young, Sequence and organisation of the human mitochondrial genome, Nature 290 (1981) 457-465.

[2] P.S. Walsh, D.A. Metzger, R. Higuchi, Chelex 100 as a medium for simple extraction of DNA for PCR-based typing from forensic material. Cetus Corporation and Illinois State Police, Biotechnics 10 (1991) 506-513.

[3] M.R. Wilson, J.A. DiZinno, D. Polansky, J. Reploge, B. Budowle, Validation of mitochondrial DNA sequencing for forensic casework analysis, Int. J. Leg. Med. 108 (1995) 68-74.

[4] M. Nei, F. Tajima, DNA polymorphism detectable by restriction endonucleases, Genetics 97 (1981) 145163.

[5] K.E. Bendall, B.C. Sykes, Length heteroplasmy in the first hypervariable segments of the human mtDNA control region, Am. J. Hum. Genet. 57 (1995) 248-256.

[6] A. Salas, D. Comas, M.V. Lareu, J. Bertranpetit, A. Carracedo, mtDNA analysis of the Galician population: a genetic edge of European variation, Eur. J. Hum. Genet. 6 (1998) 365-375.

[7] H.B.S.M. Côrte-Real, V.A. Macaulay, M.B. Richards, G. Hariti, M.S. Issad, A. Cambon-Thomsen, S. Papiha, J. Bertranpetit, B.C. Sykes, Genetic diversity in the Iberian Peninsula determined from mitochondrial sequence analysis, Ann. Hum. Genet. 60 (1996) 331-350.

[8] M.B. Richards, H. Côrte-Real, P. Forster, V. Macaulay, H. Wilkinson-Herbots, A. Demaine, S. Papiha, R. Hedges, H.-J. Bandelt, B. Sykes, Paleolithic and Neolithic lineages in the European mitochondrial gene pool, Am. J. Hum. Genet. 59 (1996) 185-203.

[9] L. Pereira, M.J. Prata, A. Amorim, Diversity of mtDNA lineages in Portugal: not a genetic edge of European variation, Ann. Hum. Genet. 64 (2000) 491-506. 